\title{
Medos Corriqueiros e Cidade: uma Resenha
}

PONTES, Williane Juvêncio. Medos Corriqueiros e Cidade: Um Análise Institucional Grupo de Pesquisa em Antropologia e Sociologia das Emoções-UFPB. Recife:

Bagaço/ João Pessoa: Edições do GREM, 2017.

Diego Amorim Novaes ${ }^{1}$

Ana Beatriz Ramos de Oliveira²

O trabalho aqui descrito consiste na análise teórico-metodológica, bem como de trajetória institucional, do GREM Grupo de Pesquisa em Antropologia e Sociologia das Emoções. É resultado da pesquisa realizada por Williane Juvêncio Pontes, enquanto bolsista PIBIC no projeto Balanço Comparativo da produção acadêmica da UFPB, Campus I, sobre a cidade de João Pessoa, Paraíba, de 1992-2012, e defendida como Trabalho de Conclusão de Curso, no Bacharelado de Ciências Sociais. Neste livro a autora se debruça sobre a produção do GREM, onde dá destaque à linha de pesquisa ESU Emoções e Sociabilidades Urbanas e ao projeto guarda-chuva Medos Corriqueiros, por entendêlos como representativos do trabalho de todo o grupo. Destaca-se aqui que o objetivo mais geral do projeto Balanço, além do mapeamento e análise da produção acadêmica da UFPB, é a identificação dos olhares dos diversos departamentos da instituição sobre a cidade de João Pessoa através da separação dos trabalhos que têm a cidade como tema, dos demais, como se realiza nesse livro de Pontes, onde a autora faz uma análise institucional do GREM, Grupo de Pesquisa atuante desde o ano de 1994, no Departamento de Ciências Sociais do Centro de Ciências Humanas, Letras e Artes da UFPB.

O projeto guarda-chuva Medos Corriqueiros, do GREM, congrega uma série de subprojetos $^{3}$, atuando desde 1999, quando de sua primeira inserção em campo, até a atualidade. Este projeto guarda-chuva foi escolhido como objeto de análise, por acompanhar toda a trajetória do GREM e da linha de pesquisa onde se insere, mas também

\footnotetext{
${ }^{1}$ Bolsista Pibic do GREM/UFPB sob orientação do Prof. Dr. Mauro Guilherme Pinheiro Koury. Email: diegoanovaes@gmail.com

${ }^{2}$ Bolsista Pibic do GREM/UFPB sob orientação do Prof. Dr. Mauro Guilherme Pinheiro Koury. Email: bia3ramos@gmail.com

${ }^{3} O$ Vínculo Ritual: Um estudo sobre sociabilidade e modos de vida entre jovens no urbano contemporâneo (2002-2006), O Parque Solon de Lucena: Espaço Público, potencial de urbanidade e desenvolvimento da cidade (2005-2006), O Bairro do Roger: História, memória e estigma (2007-2008), Sujeira e Imaginário Urbano (2009-2011), Confiança e Vergonha: Uma análise do cotidiano nos processos de interação cotidiana sob intensa pessoalidade (2012-atual), Observatório sobre Medo, (2012-atual) e Balanço Comparativo da produção acadêmica da UFPB, Campus I, sobre a cidade de João Pessoa, Paraíba, de 1992-2012 (acrescido para 2016).
} 
por envolver uma grande quantidade de subprojetos a ele agregados, ainda encontrar-se em andamento, e contabilizar uma grande produção sobre a cidade de João Pessoa. Na contabilização de Pontes, até 2016 o projeto contava com 128 produções acadêmicas sobre a cidade de João Pessoa. Destas, 60 consistiam em artigos publicados em periódicos, 07 livros, 11 monografias aprovadas, 05 dissertações de mestrado, 34 trabalhos em anais de congresso e 11 capítulos de livro.

O fundamento teórico do projeto, apesar de sua larga diversidade analítica em vista dos diversos trabalhos executados em seu interior, é a categoria identificada por Koury (2002) dos Medos Corriqueiros MC. Pontes (p.15), citando Koury (2008, p. 14), informa que o autor identifica o medo como "[...] um sentimento que rege o comportamento humano em toda e qualquer forma de sociabilidade, fazendo parte da experiência social de uma determinada situação"”.

Apesar de sua conotação negativa pelo senso comum, para Koury, de acordo com a análise de Pontes (p. 34), o medo não é visto apenas como um elemento de subordinação, retraimento e repulsa, fomentando estigmas, estranhamento, individualização e hierarquização grupal e/ou individual. Esta emoção também assume um aspecto transgressor, inovador, organizador e criador de novas sociabilidades, causando estranhamento e provocando reações de proximidade, refazendo novas possibilidades de relações sociais.

Pontes destaca, ainda, o caráter múltiplo e cooperativo, preservador e disseminante, do projeto MC. Na medida em que se trata de um projeto guarda-chuva, explica a autora, o projeto MC permite o desenvolvimento de vários núcleos de pesquisa autônomos entre si mas que estão em constante diálogo, podendo assim construir um mosaio científico, no sentido beckeriano (BECKER, 1993), do objeto analisado, no caso, a cidade de João Pessoa. Além disso, continua, essa atividade está centrada em uma memória institucional (Ayello et al, 2008; Bosi, 1993; Nora, 199; Santos, 2009), entendida como "[... ]elemento investigativo que identifica historicamente os estudos e análises desenvolvidos por um determinado grupo ou instituição" (Pontes, 2017, p. 23).

\footnotetext{
4"O conceito de situação no projeto MC é entendido através da definição interacionista dada por Thomas (citado em Berger, 2001, p. 107) de uma moralidade estipulada segundo os moldes acordados entre aqueles que dele participam e entre os que a definem."
} 
O GREM, como explica Pontes, está vinculado ao Departamento de Ciências Sociais e à Pós-Graduação em Antropologia da UFPB, e tem como preocupação principal a análise da emergência da individualidade e do individualismo no Brasil urbano contemporâneo, se concentrando na investigação da cultura emotiva, e na relação entre as culturas objetiva e subjetiva. A linha de pesquisa ESU, por sua vez, analisa a cidade de João Pessoa através das temáticas de sociabilidade urbana, ideal de progresso, fotografias do urbano, sentimento de pertença, emoção de luto, sentimento de perda, noção de morte e de morrer e a emoção do medo. O MC, então, dentro da ESU e do GREM, se preocupa em identificar as novas sociabilidades advindas do processo de modernização conservadora por que passa a cidade de João Pessoa a partir de 1920 e com intensidade a partir de 1970, caracterizada pela individuação e o anonimato.

A análise do GREM empreendida por Pontes, e exposta neste livro, está organizada na divisão em (1) fases pré-organizativas, (2) a efetividade do GREM e do projeto MC e (3) investigação do mosaico simbólico construído pelo grupo de pesquisa.

No capítulo "O Projeto de Pesquisa Medos Corriqueiros: fases pré-organizativas", Pontes identifica a etapa germinal do projeto como indo dos anos 1983 a 1999 e tendo duas fases. A primeira fase, que corresponde ao período entre 1983 e 1994, analisada através do trabalho do principal pesquisador do futuro grupo, Mauro Koury. Este, no recorte citado, se preocupa com as temáticas da questão de classe, do sindicalismo e dos movimentos sociais.

Em relação aos conceitos, a autora percebe uma transição, ao final do período destacado, do homem comum pobre para o homem comum. Tal mudança indica uma preocupação maior com a subjetividade do indivíduo em oposição à sua posição social na sociedade hierarquizada. Esse indivíduo é estudado enquanto apreendido pelo discurso modernizador e pela ideologia do progresso que pautam políticas de higienização e têm o trabalho como disciplinador. O principal projeto desse período foi o Fontes para a História da Industrialização do Nordeste: 1889-1980, do qual Koury foi coordenador.

A segunda fase, cujo recorte vai de 1994 a 1999, é composta por duas linhas de pesquisa: Fotografia, Cidade e Pertença e Processo de Luto e Morte no Brasil Contemporâneo. Dentro do primeiro, o projeto Fotografia, Cidade e Pertença, responsável por 
artigos, livros e capítulos de livros, além de três dissertações de mestrado, é preenchido pelas temáticas de ideal de progresso e modernização urbana; em como a imagem da cidade é criada em fotografias; o sentimento de pertencimento e orgulho da cidade; bem como a ação dos produtores sociais nesse movimento. Na segunda linha, o foco passa a ser o luto e a morte enquanto códigos capturados da sociedade relacional para a urbana contemporânea, e transformados em fatores individualizantes e isolantes. É neste momento que se verifica uma aproximação clara de Koury com as categorias da emoção, se preocupando em identificar as mudanças nas atitudes e relações emocionais com o crescimento da sociedade urbanizada brasileira.

No capítulo "Medos Corriqueiros: construindo um projeto de pesquisa", referente a atuação efetiva do projeto MC, Pontes o analisa entre 1999, seu início, a 2016. A autora então, após suas leituras e utilizando critérios que serão explicitados, divide esse período em três momentos. O primeiro momento, 1999-2008, corresponde à consolidação do arcabouço conceitual que fundamenta a análise da cidade pelo GREM. Nele se encontram três subprojetos. O segundo momento, 2009-atual, corresponde a uma complexificação analítica e conceitual, e também é composto por outros três subprojetos. O terceiro momento, 2012-atual, corresponde à criação de um novo objeto de análise, porém ainda no interior do projeto guarda-chuva MC, sobre a produção acadêmica da UFPB, e tem como projeto central o Balanço Comparativo da Produção acadêmica do campus I da UFPB sobre a cidade de João Pessoa.

No primeiro momento do projeto guarda-chuva MC, destaca-se a produção as monografias de Márcio Vilar (2001), Rivamar Silva (2003), Alessa Souza (2003), Andréia Silva (2004) e Anne Gabrielle Souza (2004). Todos eles se preocupam com a construção do imaginário social do medo entre os moradores de alguns bairros da cidade de João Pessoa. Discutem a questão do medo, do controle social, da pobreza e da memória num contexto de urbanização e individualismo crescentes, frutos da modernização conservadora por que passa a sociedade, e utilizam o arcabouço conceitual do medo, dos medos corriqueiros, da pertença, da semelhança e dessemelhança, do individualismo, da confiança e do segredo, entre outros.

Numa segunda etapa deste primeiro momento do MC, Pontes identifica o início 
de um novo recorte analítico: a rua. Neste sentido, os trabalhos de Alexandre Almeida (2005) e Francisco Cavalcanti Filho (2005) analisam a rua tanto enquanto lugar público de pertença e reconhecimento mútuo entre os vizinhos, quanto de estranhamento na medida em que é trafegada por transeuntes. Também são analisados, na cidade de João Pessoa, os circuitos de lazer, como no trabalho de Leandro Souza (2005).

Além destes trabalhos, o MC também foi responsável, nesta primeira fase, por três subprojetos: (1) O Vínculo Ritual. Um estudo sobre a sociabilidade e modos de vida entre jovens no urbano brasileiro contemporâneo (2002-2006) que estudou um grupo de apoio a jovens de história difíceis e utilizou como arcabouço as noções de pertença, identidade, códigos morais, confiança, lealdade, o sistema de nominação e o controle social; (2) Parque Solón de Lucena: Espaço público, potencial de urbanidade e desenvolvimento da cidade (2005-2006) que estudou a urbanização da cidade com foco neste parque, levantando sentimentos ambivalentes nutridos pelos cidadãos da cidade. Por um lado nutrem amor e orgulho pelo patrimônio, na medida em que é o cartão postal dela, e também ódio e mal-estar na medida em que é abandonado pelo poder público e se torna antro de "marginais"; e por fim, (3) O Bairro do Roger: história, memória e estigma (20072008) que trabalhou sobre a construção do imaginário acerca da divisão hierárquica criada no bairro popular do Roger, entre Alto Roger, considerado civilizado, e o Baixo Roger, associado à barbárie e à pobreza.

O segundo momento do MC, compreendido aqui entre os anos 2006 e 2016, possui, entre outros, os subprojetos Sujeira e Imaginário Urbano (2009-2011), Confiança e Vergonha: Uma análise do cotidiano da oralidade (2010-2011) e Sociabilidade e conflito nos processos de interação cotidiana sob intensa pessoalidade (2012-atual).

O primeiro projeto, Sujeira e Imaginário Urbano teve o objetivo de analisar o conceito de sujeira no imaginário urbano brasileiro. As pesquisas realizadas em cinco capitais João Pessoa-PB, Recife-PE, Belém-PA, Curituba-PR e Brasília-DF, definiram o conceito em três categorias gerais: (1) moralidade, falta de higiene e falta de confiança, (2) violência urbana e (3) a ética, que diz respeito à falta de consciência ecológica e falta de respeito com a Coisa Pública.

O projeto Confiança e Vergonha se propôs a analisar a dinâmica social no bairro 
do Varjão/Rangel a partir de um evento conhecido como "chacina do Rangel". Trabalha a partir do sentimento de vergonha social bem como o papel da mídia na espetacularização do ocorrido e na incitação do pânico moral.

O projeto Sociabilidade e Conflito também analisa o bairro do Varjão/Rangel em suas sociabilidades. No entanto, aprofunda a discussão analisando, além dos laços de confiança, lealdade e gratidão, as hierarquias sociais construídas a partir de discursos sobre o outro, classificando-o como bom ou mau.

O terceiro momento do MC, identificado por Pontes, corresponde ao início do subprojeto Balanço Comparativo da produção acadêmica da UFPB, Campus I, sobre a cidade de João Pessoa, Paraíba, de 1992-2012, ou seja, ao deslocamento dos esforços do MC para a análise da produção acadêmica da UFPB afim de identificar seus olhares sobre a cidade de João Pessoa, como já explicitado.

No capítulo "Mosaico científico sobre a cidade de João Pessoa", Pontes vai descrever as diversas formas em que se encaminham as pesquisas dentro do projeto Medos Corriqueiros. O mosaico científico nada mais é do que essas diversas formas de olhar para o mesmo objeto, no caso específico do projeto MC, o Medo é o plano de fundo de análise dessas pesquisas e atua como "fenômeno que organiza as formas de sociabilidade urbana" (p. 95), a partir desse medo as relações entre os indivíduos dessa sociedade vão se formular ou reformular dentro de um determinado ambiente. Nesse capítulo, Pontes apresenta o estudo de alguns bairros de João Pessoa que foram analisados de diversas formas teórico metodológico, as relações de permanências, as modificações dos ambientes com o passar do tempo e as trocas sociais que são definidas a partir desses medos, dessa memória, do sentimento de pertencimento etc.

Já no subtópico dentro do capítulo "A cidade de João Pessoa sob a ótica dos medos corriqueiros: configurações urbanas, sociais e emocionais", Pontes faz um recorte histórico onde inicialmente conta a história da formação da cidade de João Pessoa, umas das mais antigas cidades do Brasil, e mostra que desde o período colonial já havia uma relação de diferencial social entre a elite e a pobreza urbana local. João Pessoa passa a se direcionar em novas propostas de progresso, no final do século XIX até a chegar ao seu "auge" nos anos 20 ou 30 do século XX. O progresso chega com uma característica 
de higienizar a cidade afastando o que é "feio e sujo" dos ambientes públicos, além da divisão social dos "pobres e vagabundos" que retardavam o caminho do progresso, e os ricos que contribuíam com trabalho para o desenvolvimento.

No segundo tópico do capítulo, "Delimitações e separações", Pontes se refere ao mosaico das separações societárias, em 1970 mais bairros foram criados na cidade de João Pessoa, se aprofundando a diferenciação entre bairros periféricos, populares e nobres. A orla marítima da cidade tem o seu apogeu, o que redirecionou a infraestrutura da cidade, além das formas de lazer.

Segundo Pontes, essas mudanças ditam novos padrões de consumo, o turismo cresce na cidade e é uma tendência dos gestores torná-la cada vez mais atraente para o consumo, a reforma do centro histórico, do Varadouro com a expropriação das populações permanentes no espaço, uma forma de mascarar a pobreza. A cidade passa a ter um caráter heterogêneo, a divisão de classe entre os bairros gera uma individualização, o sentimento de insegurança, a violência, a cidade vai se reformulando a partir desses novos padrões de relacionamento e de medo, a mídia local acentua os movimentos de violência dentro dos bairros o que acaba rotulando os perigosos dos não perigosos, além da sensação de medo entre os bairros. De acordo com o mosaico de pesquisas no interior do projeto guarda-chuva MC, segundo Pontes (p.103), o processo de modernização atinge diretamente cotidiano do indivíduo, traz mudanças espaciais, sociais, emocionais e culturais, e constrói novas vivências e práticas sociais fundadas em novas formas de sociabilidade, via imaginário social sobre o medo. A urbanidade, trouxe inúmeras alterações às relações sociais, onde as remodelações espaciais condicionam, de forma recíproca, as remodelações sociais. Ambas se configurando em constante sintonia.

Em "Configurações de uma nova sensibilidade no urbano pessoense" um outro tópico do capítulo, Pontes fala sobre as análises feitas no interior do projeto MC, que identificam as transformações emocionais e sociais, a diferenciação do público e privado dentro dessas relações, as tradições os laços afetivos, as amizades as semelhanças com a vizinhança. Essas relações são modificadas com o passar dos tempos com os novos códigos sociais, e o individualismo a privatização das emoções passa a tornar o indivíduo blasé. A cidade de João Pessoa mescla as relações modernas e tradicionais, 
e os habitantes revelam vários sentimentos em relação a cidade, amor, ódio, orgulho, vergonha, medo. A modernização leva a identidade do cidadão através do seu cotidiano, a sensação de medo das mudanças da cidade ao mesmo tempo o saudosismo na memória do que a cidade já foi um dia, como ele se relacionava com ela, os seus antigos sentimentos, antigos hábitos, se refletem nessas novas sensibilidades pessoenses, que permeiam tanto os bairros populares como os bairros de classe média e média alta.

Já em "Dinâmica dos Bairros, Ruas e Parques da Cidade" Pontes fala sobre os bairros nobres (como Tambaú e Estados), populares (Varadouro, Tambiá, Roger, Cruz das Armas, Mangabeira) e periféricos (a comunidade de Porto do Capim, Illa do Bispo, Valentina de Figueiredo, Varjão/Rangel) da cidade. Esses bairros foram estudados por pesquisadores do GREM sobre seus sentimentos de pertença à cidade e ao bairro pelos moradores, depois do grande processo de modernização feito desde os anos de 1970, em estudos sobre a nova reformulação dos bairros na cidade, e as novas formas de sociabilidades emergidas no processo.

Pontes nos leva a compreender com o mosaico dos bairros nobres, populares e periféricos de João Pessoa com o levantamento dos estudos sobre os medos corriqueiros, que faz a ponte sobre os diversos olhares dos pesquisadores do GREM, envolvidos na pesquisa guarda-chuva $\mathrm{MC}$, em relação à cidade. Vimos as relações dos bairros populares, com uma característica mais tradicional do se relacionar, de solidarizar, enquanto os bairros nobres, carregam consigo a característica de individualização cada vez maior, além do afastamento do que é estranho e que causa medo.

Em "Análises dos Parques Circuitos de Lazer" Pontes analisa os estudos dos dois ambientes de lazer tradicionais na cidade de João Pessoa, são eles o Parque Solon de Lucena a Lagoa e o Parque Arruda Câmara a Bica. Como podemos ver no levantamento de Pontes nesse capítulo trabalha com a construção do mosaico científico de Becker nos estudos do projeto MC a partir do medo como plano de fundo para essas pesquisas. As relações da rua, dos bairros, das formas de sociabilizar com os outros, a empatia, a memória, o pertencimento a tradição, a amizade, a diferença de classes dentro dos bairros e suas fronteiras, o sentimento de medo em relação a determinadas populações, mas mudanças da cidade que vive uma constante higienização até os dias atuais com projetos 
de urbanização e limpeza dos lugares habitados por classe mais baixas da sociedades, além das resistências desses bairros, e dos aspectos morais adotados por esses indivíduos na distinção dentro desses bairros quem é de "bem" ou não. O papel da mídia também é visto com um potencializador dos estigmas criados dentro dos bairros e do medo difundido.

O livro de Pontes é, assim, se não um levantamento escrito em camadas, onde na primeira parte ela se debruça em um período pré GREM, com a história de pesquisa do seu fundador Mauro Koury, até seus novos caminhos pelo grupo. Depois, em um segundo momento, Pontes aponta a formação das linhas de pesquisa, até abordar a projeto guarda-chuva MC que, em uma terceira parte, observa no seu levantamento o grande volume de produção existente neste projeto sobre a cidade de João Pessoa sob a ótica da antropologia das emoções. A partir dos levantamentos das fases do projeto e da construção do grupo de pesquisa, Pontes mostra o seu próprio trabalho, como uma análise institucional de um grupo de pesquisa, o GREM, como mais um dos diversos olhares sobre a cidade de João Pessoa, no interior da pesquisa MC, agora na sua nova fase compreensiva da produção acadêmica sobre a cidade pelos pesquisadores de toda a UFPB campus I. O que permite uma visão do mosaico científico sobre a cidade de João Pessoa, a partir dos diversos olhares disciplinares que enfocam esses estudos, nos diversos grupos de pesquisa do campus I da UFPB.

O que torna o livro importante para a compreensão de um esforço analítico de um grupo de pesquisa e de um projeto guarda-chuva, em sua construção de uma cidade a partir de uma visão de mosaico científico. Mas, também, no seu aspecto de pesquisa partilhada e solidária onde cada pesquisador monta a partir de um projeto maior o seu próprio projeto, cujas conclusões se juntam analiticamente ao já feito e serve, como um banco de dados em movimento a outros tantos projetos novos que a ele se agregam. Portanto, o recomendamos a leitura.

\section{Referências}

ALMEIDA, Alexandre. Sociabilidade, Pertença e Medos Corriqueiros: Estudo de uma rua no bairro de Valentina de Figueiredo João Pessoa ? Paraíba. TCC. João Pessoa: CCS/UFPB, 141. 
AYELLO, Maria Aparecida Bezerra et al. A abordagem da produção científica como memória institucional: o caso da biblioteca do Instituto de Geociências da USP. São Paulo: Anais do XIV Seminário Nacional de Bibliotecas Universitárias, 2008.

BECKER, Howard. Métodos de pesquisa em Ciências Sociais. São Paulo: HUCITEC, 1993.

BOSI, Ecléa. A pesquisa em memória social. Psicologia, v.4, n.1/2, p. 277-284, 1993.

CAVALCANTI FILHO, Francisco de Assis Vale. Convívio e interação social: os c'digos de afeição e de estranhamento, os medos corriqueiros e a sociabilidade em uma rua. TCC. João Pessoa: CCS/UFPB, 2008.

KOURY, Mauro Guilherme Pinheiro. Medos Corriqueiros: A contrução social da semeIhança e da dessemelhança entre os habitantes urbanos das cidades brasileiras na contemporaneidade. Projeto GuardaChuva de Pesquisa, GREM: João Pessoa, 2002.

KOURY, Mauro Guilherme Pinheiro. De que João Pessoa tem Medo? Uma abordagem em Antropologia das Emoções. EdUFPB: João Pessoa, 2008.

NORA, Pierre. Entre Memória e História. A problemática dos lugares. Trad. Yara Aun Khoury. São Paulo: Projeto de História, 1993, p. 7-28.

SANTOS, Cláudia. Memórias de docentes universitários e a produção do conhecimento do PPGE/UFMG. Esse. Belo Horizonte: UFMG, 2009.

SILVA, Andréia Vieira da. Sob a ótica do medo: Um estudo de caso no bairro dos Estados, João Pessoa ? PB. TCC. João Pessoa: CCS/UFPB, 2004.

SILVA, Rivamar. Tambiá ? medo cultura e sociabilidade: Um estudo sobre o bairro de Tambiá, João Pessoa-PB. TCC. João Pessoa: CCS/UFPB, 2003.

SOUSA, Anne Gabriele Lima. Tambaú: Pertença e fragmentação sob a ótica do medo. TCC. João Pessoa: CCS/UFPB, 2004.

SOUZA, Alessa C. P. de. Uma análise do bairro de Cruz das Armas sob a ótica do medo. TCC. João Pessoa: CCS/UFPB, 2003.

VILAR, Márcio da Cunha. Medo na cidade: Uma experiência no Porto do Capim. TCC. João Pessoa: CCS/UFPB, 2001. 